\title{
UMA LEITURA FOUCAULTIANA DA RELAÇÃO CONJUGAL DOS ANTIGOS
}

\author{
Ana Lúcia dos Santos e Santos ${ }^{1}$
}

RESUMO: No presente texto, pretendemos abordar a relação conjugal na ética antiga, elaborando reflexões que de início mostrem como o indivíduo antigo se portava diante da prática dos prazeres, bem como era a relação entre os casais, o escravo, o rapaz e a concubina. Para os antigos, importava a maneira como se procediam diante das práticas dos prazeres, a maneira como mantinham o domínio de si e não como constituir uma moral que delimitasse o certo e o errado. Importavam-se com a maneira de como se manter temperante, sendo capaz de ter um autocontrole sobre si mesmo e também poder governar a cidade. É nessa conjuntura que teremos subsídios para a análise da relação conjugal, a qual as mulheres deviam obediência ao homem e seu esposo, e o homem devia obediência a si mesmo, uma vez que necessitava manter-se moderado para isso. 
PALAVRAS-CHAVE: Temperança, prazer, prática, relação conjugal.

ABSTRACT: In the present text, we intend to approach the conjugal relationship in the old ethics, elaborating reflections that at first show how the old individual behaved before the practice of the pleasures, as well as was the relation between the couples, the slave, the boy and the concubine. For the ancients, it mattered how they proceeded in the face of the practices of pleasures, the way they maintained self-control and not how to constitute a morality that delimited right and wrong. They cared about how to remain temperate, being able to have self-control over themselves and also be able to govern the city. It is at this juncture that we will have subsidies for the analysis of the conjugal relationship, to which women owed obedience to man and her husband, and man owed obedience to himself, since he needed to remain moderate for it.

KEYWORDS: Temperance, pleasure, practice, marital relationship 
Em sua obra, História da sexualidade II, O Uso dos prazeres (1984), Michel Foucault aborda a ética antiga, especificamente como os antigos se portavam diante dos prazeres. Em todo o percurso da análise dos antigos, Foucault (FOUCAULT, 2014 d, v: IX, p. 216) tentou verificar o porquê de a modernidade tentar fazer do comportamento sexual uma questão moral. Desse modo, ao analisarmos a ética antiga perceberemos que o interessante para os antigos era a maneira como se conduziam diante das práticas dos prazeres, a maneira como mantinham o controle de si. Em outras palavras, as culturas Grecoromanas se importavam com uma arte de viver, de ser capaz de ter um equilíbrio sobre si mesmo para também poder governar a cidade. Dessa maneira, Foucault quis entender como a atividade sexual foi constituída como problema moral através de técnicas de si, técnicas essas que permitiriam o domínio sobre os prazeres e os desejos.

Dessa maneira, Foucault afirma existir uma enorme dificuldade em encontrar nos gregos uma noção parecida com a noção moderna de sexualidade, qual seja, "uma noção que se refira: A uma entidade única e que permita agrupar como sendo da mesma natureza, derivando de uma mesma origem ou fazendo intervir o mesmo tipo de causalidade, fenômenos diversos" (FOUCAULT, 1984, p. 47). Por mais que os gregos utilizassem um vasto vocabulário para fazer referência às práticas sexuais, de 
forma geral, no que dizem respeito às relações sexuais, os termos referidos são vagos. $\mathrm{Na}$ antiguidade não existia a noção de sexualidade tal como a modernidade a aborda, o que existiam eram os aphrodisia ${ }^{2}$. De acordo com Foucault, para os gregos existia a substância ética, que "eram atos ligados em sua unidade ao prazer e ao desejo; eram o que eles chamavam de aphrodisia; os quais eram tão diferentes da 'carne' cristã quanto a sexualidade" (FOUCAULT, 2014 d, v: IX, p. 224). Foucault (1984, p. 47) traz para o texto o adjetivo "Ta aphrodisia", utilizado pelos gregos, sublinhando que a "diferença entre os conjuntos nocionais torna difícil a tradução exata do termo", e que a ideia moderna de "sexualidade" abarca um campo bem maior e visa outra realidade, pois possui funções diferentes. Daí a importância de analisar os quatro tipos principais de "problemas" - a propósito do corpo, do casamento, dos rapazes e da verdade ${ }^{3}$ - que se relacionam com a conduta sexual, ao "distinguir alguns traços gerais que lhes serviram de quadro de referência porque eram comuns às diferentes reflexões sobre os aphrodisia" (FOUCAULT, 1984, p. 48).

Ao mencionar os aphrodisia, Foucault esclarece que os gregos não deram nenhum testemunho em seu pensamento histórico que esteja relacionado ao cuidado de delimitar o que entendiam por aphrodisia do ponto de vista da lei, "quer se tratasse de fixar a natureza da coisa designada, de delimitar a extensão de campo, ou de 
estabelecer o catálogo de seus elementos" (FOUCAULT, 1984, p. 51). Não faria sentido a pergunta pelo quadro que definisse o legítimo, o permitido ou o normal, com relação aos gestos proibidos para os antigos, diferentemente do que acontece com as doutrinas cristãs, a qual o pastor delimita o que fazer ou evitar, quais carícias iniciais são permitidas e etc. Tampouco estava em indagação, no campo dos aphrodisia, algo que estivesse relacionado ao cuidado da questão da carne para os cristãos e da sexualidade para a modernidade. $\mathrm{O}$ que existiam eram preocupações sobre a melhor idade para casar e ter filhos, as estações mais propícias para se praticar as relações sexuais. Com efeito, os antigos tratavam da questão do prazer, delimitando o que entendiam por prazer, isso acontecia na conjuntura dos aphrodisia.

No que concerne às figuras do macho e da fêmea, a experiência da carne é comum tanto em um quanto no outro, mesmo não tomando a mesma forma. Nessa conjuntura os aphrodisia são considerados atividades que implicam a participação de dois atores, funcionando da seguinte forma: cada um terá o seu papel e sua função, a qual diz quem exerce e sobre qual é exercida a atividade. $\mathrm{Na}$ concepção de Foucault (1984, p. 60), a linha que delimita a função e o papel, passa especificamente entre o homem e a mulher, uma vez que existe uma enorme diferença entre o mundo dos homens e o das mulheres em muitas sociedades 
antigas. Dessa forma, os atores ativos são os homens, que exercem as atividades, já os passivos são as mulheres, os rapazes e escravos, que são os objetos de prazer; e "o excesso e a passividade são, para o homem, as duas formas principais de imoralidade na prática dos aphrodisia" (FOUCAULT, 1984, p. 61).

Segundo Foucault (1984, p. 61), o ato e o prazer não devem ser considerados maus, pois eles tendem a restaurar um modo de ser mais completo do homem, sendo aí, a atividade sexual vista de forma natural, pois é a partir dela que é possível a espécie se reproduzir. Essa é a principal tarefa do relacionamento conjugal, de modo que ao esposo era recomendado ter filhos somente com sua esposa, a fim de preservar a legitimidade dos filhos. Contudo, segundo Foucault, por mais natural que seja, é necessário atenção e cuidado do homem nas suas práticas. Nas palavras de Foucault:

Por mais natural e mesmo necessária que possa ser, ela não é menos objeto de um cuidado moral; ela pede uma delimitação que permita fixar até que ponto, e em que medida, é conveniente praticá-la. Entretanto, se ela pode ter algo a ver com o bem e com o mal, não é detrimento de sua naturalidade, ou porque esta teria sido alterada, é em razão mesmo da maneira pela qual a natureza dispôs (FOUCAULT, 1984, p. 62). 
Foucault (1984, p. 63) elucida que, para os gregos, os prazeres são marcados por dois traços. $\mathrm{O}$ primeiro seria o caráter inferior: $\mathrm{O}$ prazer sexual aí seria tido como não portador de males, mas inferior porque é comum aos animais e aos homens. $\mathrm{O}$ segundo caráter é o do prazer condicionado e de extrema vivacidade. O filósofo francês faz a retomada do pensamento grego não com o intuito de vivenciar a ética grega, e sim para compreender e problematizar, a partir dos antigos, o prazer na modernidade.

Ora, se o filósofo francês analisa a ética antiga não querendo justificar as interdições, não estamos caindo em um paradoxo? Os gregos praticaram, ainda que de modo velado ou com reservas, a relação entre homens e rapazes, contudo, os filósofos da época criaram uma moral de abstenção. Os gregos também admitiram que os homens pudessem ter relações fora do casamento, no entanto os moralistas criaram o princípio, segundo o qual, o homem só poderia ter relação com sua esposa. Os gregos não viam a atividade sexual como um mal, porém os médicos da época se inquietaram com a relação entre a atividade sexual e a saúde. Segundo Foucault (1984, p. 125), à primeira vista sim, parece existir um paradoxo. No entanto, no que diz respeito às relações entre atividades sexuais e saúde, por exemplo, a organização dessa atividade não se definia na 
relação entre o normal e o anormal, entre o saudável e o patológico.

De acordo com Foucault $(1984,174)$, os gregos não procuraram com a arte erótica desenvolver o ato sexual e também não desenvolveram uma legitimação institucional como ocorreu com o cristianismo. O que caracteriza a ética antiga é uma relação de si para si mesmo, a possibilidade de um sujeito que é mestre de sua própria conduta, que deve saber quando convém ou não praticar determinado ato. Assim, Foucault (1984, p. 145) esclarece que os aphrodisia são considerados em blocos, como uma atividade onde o que importa é "se ela ocorre, com que frequência, e em que contexto". As culturas greco-romanas e helenísticas, a partir do século IV a. C., criaram um preceito de grande importância para a sua época e para as culturas ulteriores. Foucault (2014 d, v: IX, p. 228) denomina esse preceito de "cuidado de si", epimeleia ${ }^{4}$ heautou. Interessam-nos, em primeira instância, no conceito de "cuidado de si", as inúmeras técnicas ascéticas desenvolvidas e posteriormente atribuídas ao cristianismo. $\mathrm{O}$ termo grego epimeleia pode ser entendido como o "cuidado de si", no entanto, de acordo com o pensamento foucaultiano, não devemos tomar esse conceito apenas como uma preocupação, uma vez que representa muito mais que uma preocupação. É um conjunto de ocupações, tais como: atividades da casa, 
tarefas de dever do príncipe, cuidados com os doentes e obrigações com os deuses e com os mortos.

Segundo Foucault (2014b, p. 54), nas culturas grecoromanas e helenísticas era notável o crescimento de um fenômeno conhecido como "individualismo". Fenômeno que ocupou espaços cada vez maiores, no que diz respeito a aspectos privados da existência. No entanto, não eram as autoridades públicas que davam conta do desenvolvimento desse fenômeno. Com o enfraquecimento do quadro político e social, as pessoas se envolviam menos com as questões relacionadas à cidade e mais com aspectos voltados para si próprios. Como resultado dessas características, as pessoas insolavam-se cada vez mais, passando a depender de si próprios, buscando na "filosofia regras de condutas mais pessoais" (FOUCAULT, 1984, p. 54).

$\mathrm{O}$ "cuidado de si" pode ser caracterizado, brevemente, pela arte da existência, em que e forma o princípio do cuidado consigo, o qual surge para fundamentar a necessidade de comandar e organizar as práticas voltadas a esse cuidado. Desde a época socrática ${ }^{5}$, existiam relatos que recomendavam o "cuidado de si", os quais afirmavam que o essencial não era o cuidado com as riquezas, com a honra, era o cuidado com a alma. Segundo Foucault, o "cuidado de si" tornou-se um imperativo que veiculou por doutrinas diferentes, tomando a forma de um comportamento, de uma atitude, de uma forma de viver. Conforme o filósofo 
francês é no quadro da cultura de si, que foram desenvolvidas as primeiras reflexões sobre a moral dos prazeres. Dessa maneira, o que à primeira vista pode nos dá indícios de uma "severidade mais marcada, austeridade acrescida" (FOUCAULT, 2014b, p. 86), não pode ser compreendido como um estreitamento das interdições. Nessas condições, o que devemos observar é a forma como o indivíduo deveria se constituir enquanto sujeito moral, uma vez que o desenvolvimento da cultura de si se deu diante de certas modificações que dizem respeito aos elementos que constituem a subjetividade moral.

Dessa forma, é necessário analisar os prazeres sexuais, para entendermos a moral dos prazeres. O prazer sexual enquanto substância ética pertencia à ordem da força, consistindo que o sujeito deveria lutar contra seus desejos, de forma que os dominasse. "A moral sexual exige... que o indivíduo se sujeite a uma arte de viver que define os critérios estéticos e éticos da existência" (FOUCAULT, 2014b, p. 87). Em outras palavras, era necessário que o indivíduo vivenciasse essa arte, que por sua vez, baseava-se em princípios da natureza ou da razão.

A cultura de si modificou o modo como o indivíduo trabalhava o "cuidado de si", uma vez que o lugar do conhecimento se mostrará com mais relevância, tornandose importante "a tarefa de se pôr à prova, de se examinar, de controlar-se numa série de exercícios bem-definidos, coloca 
a questão da verdade no cerne da constituição do sujeito moral" (FOUCAULT, 2014b, p. 87). Essa concepção de verdade possibilitava questionar como o sujeito era, o que fazia e o que seria capaz de fazer. Importava para os antigos que o indivíduo conseguisse cuidar de si mesmo, aprendendo a ser soberano de si mesmo, uma vez que a soberania assumiria a forma de dominação $e$ especificamente de um "gozo sem desejo e sem perturbação" (FOUCAULT, 2014b, p. 87). Uma forma de entender esse cuidado de si é analisando o casamento e a relação conjugal.

Foucault aborda a questão do casamento e da "fidelidade" a partir do libelo do Contra Nera, atribuído a Demóstenes. Com Contra Nera foi formulado o aforismo: "as cortesãs, nós as temos para o prazer; as concubinas, para os cuidados de todo o dia; as esposas, para ter uma descendência legítima e uma fiel guardiã do lar" (FOUCAULT, 1984, p. 183).

Essa fórmula, segundo Foucault (1984, p. 184), parece repousar sobre um sistema distinto. Isso porque, por um lado, faz funcionar o princípio de uma única esposa legítima, por outro, situa o campo dos prazeres na relação extraconjugal. No aforismo do Contra Nera, o prazer não é encontrado no casamento, só nas relações fora do casamento, sendo a finalidade do casamento reproduzir. Nessa fórmula, homens e mulheres tem papeis diferentes, 
de um lado, as mulheres, enquanto esposas, tem a obrigação de ter como único parceiro o marido, tendo toda e qualquer atividade sexual no interior da relação conjugal. As mulheres encontravam-se sobre o poder do marido, dandolhes herdeiros e cidadãos legítimos. Por outro lado, os homens tinham um limite de obrigações para com suas esposas, porém, a exclusividade da relação sexual entre o casal não fazia parte dessas obrigações, "o casamento de um homem não o liga a sexualidade" (FOUCAULT, 1984, p. 187).

$O$ adultério, na moral antiga, não consistia numa ruptura do vínculo por partes iguais dos cônjuges, só era considerado infração à medida que fosse cometido pela mulher: "é o status matrimonial da mulher, jamais o do homem, que permite definir uma relação como adultério" (FOUCAULT, 1984, p. 187). Aqui, é necessário esclarecer que no pensamento grego não houve uma categoria de fidelidade recíproca, essa era uma característica da pastoral cristã, a qual introduziu uma espécie de direito sexual de valor moral, "com efeito jurídico e de efeito religioso" (FOUCAULT, p. 187). Na relação matrimonial da ética antiga, o princípio de um monopólio sexual que obrigava a exclusividade entre os parceiros não se enquadrava, uma vez que a mulher pertence ao homem, mas não ocorre o mesmo com o homem, ele pertence a si mesmo. 
Todavia, é preciso que entendamos que essas relações não eram simples, como supostamente poderíamos pensar à primeira vista. De acordo com Foucault (1984, p. 188), seria inexato pensar a conduta da mulher (esposa) como "imperiosamente fixada", enquanto o homem (esposo) tem total liberdade no que diz respeito à prática dos prazeres. Foucault esclarece que havia testemunhos da existência de ciúmes sexuais, de modo que "as esposas reprovavam comumente os seus maridos pelos prazeres que eles iam buscar alhures, e a mulher volúvel de Eufíleto o censura por suas intimidades com uma pequena escrava" (FOUCAULT, 1984, p. 188).

De modo geral, existiam restrições para o homem que se casava, esperavam-se algumas modificações no seu modo de agir no uso dos prazeres (conduta sexual). Alguns moralistas, segundo Foucault (1984, p. 189), recomendavam que os homens casados não deveriam sentir-se livres para praticar os prazeres como se não fossem casados. Sabemos que a quantidade de relatos e testemunhos é pequena, no entanto, diante do exposto é possível afirmar que nesse momento os moralistas estavam implantando uma nova ética, por assim dizer. Qual o real movimento, se é que há, pelo qual se incitou esse tipo de comportamento, uma vez os homens não eram obrigados, perante a lei, a não praticar os prazeres de forma livre? Consistiria, esclarece Foucault (1984, p. 189), no fato de que a relação entre os esposos e 
suas esposas não tinham nenhuma outra função, a não ser aquela que liga a família, aquela que forma uma aliança, com o objetivo de produzir uma descendência legítima. Diferentemente do mundo moderno, a fidelidade, o respeito ao matrimônio e todas as práticas públicas relacionadas à monogamia, não eram regidos por uma lei ou norma, mas por um código moral legítimo e efetivo enquanto emergente da prática cotidiana dos prazeres, em nome de uma estética da existência, e não em função de um princípio transcendental, tal como aquele subentendido no respeito aos mandamentos cristãos. Os homens casados só encontrariam uma descendência legítima à medida que gerassem um filho com a esposa legítima, uma vez que ao se relacionar com uma concubina e dessa relação gerasse uma criança, essa criança não seria considerada herdeiro e nem filho legítimo, afim de que posteriormente pudesse tornarse um bom cidadão segundo os preceitos da cidade. Nas palavras de Foucault:

O prazer é a única coisa que a cortesã pode dar; a concubina pode proporcionar, além disso, as satisfações da existência cotidiana, mas somente a esposa pode exercer uma certa função pertinente ao seu próprio status: dar filhos legítimos e garantir a continuidade da instituição familiar (FOUCAULT, 1984, p. 190). 
Dessa forma, à primeira vista, ao analisarmos a ética antiga, podemos observar a necessidade de uma separação entre os prazeres, as paixões e o casamento. No entanto, de acordo com Foucault (1984, p. 190), essa ideia de separação não resume o que era a ética antiga. Isso porque podemos notar possíveis disparidades, no que diz respeito a esses princípios: por um lado os cidadãos eram conduzidos a viverem com a ideia de que o homem tinha a liberdade perante o uso dos prazeres, fora do casamento; por outro, alguns moralistas defendiam que os homens deveriam mudar seus hábitos após o casamento.

Todavia, podemos cair num paradoxo ao percorrer por esse caminho. O homem (esposo) era livre para praticar seus prazeres com quem achasse conveniente, ou teria que praticá-los exclusivamente com suas esposas? Na concepção de Foucault (1984, p. 190/191), de tanto se querer distanciar a moral austera antiga dos princípios da moral cristã, houve um fenômeno de aproximação.

Tenta-se, frequentemente, reconhecer nesses textos onde a boa conduta do marido é pensada, valorizada e regulada sob a forma da "fidelidade sexual", o esboço de um código moral ainda inexistente: aquele que imporá simetricamente, aos dois esposos, na mesma obrigação de somente praticar as relações sexuais na união conjugal, e o mesmo dever atribuir- 
lhes a procriação como fim privilegiado senão exclusivo. (FOUCAULT, 1984, p. 191).

Ora, de acordo com o filósofo francês, entender os princípios da austeridade filosófica antiga não é fazer uma análise aproximando os antigos dos modernos ou distanciálos, é antes fazer uma análise que esteja de acordo com os princípios que vigoravam na época: em razão de a ética antiga problematizar a conduta sexual do homem, não com o intuito de valorizar e regularizar a forma de "fidelidade", a qual se torna presente na ética cristã. Isso porque o homem antigo, antes da "função" de esposo, era um chefe, um chefe da casa, nas funções referentes ao trabalho com a lavoura, com os escravos. Uma autoridade que deveria exercer seu poder perante os subordinados, e é por isso, de acordo com Foucault (1984, p. 192), que a reflexão sobre a boa conduta do homem e o casamento está ligada a uma reflexão da casa e da propriedade doméstica.

Dessa forma, existia uma natureza de obediência tanto no homem quanto na mulher, no entanto com finalidades diferentes. A mulher tinha como obrigação controlar seus prazeres, pois estava sob o poder de seu marido. Já para o homem, a restrição as práticas dos prazeres se fazia devido ao fato do mesmo exercer o poder, tendo então que demonstrar controle e domínio de si. "Não ter relação com o esposo é para a mulher uma consequência do fato de que 
ela está sob o seu poder. Não ter relação a não ser com sua esposa é, para o marido, a mais bela maneira de exercer seu poder sobre a mulher" (FOUCAULT, 1984, p. 192).

Assim, o homem vive em um combate constante, sendo possíveis inúmeras vitórias. Porém, "a primeira e mais gloriosa", na análise de Foucault, é a conseguida sobre si mesmo, e "o mais vergonhoso" dos fracassos consiste em ser vencido por si mesmo. A vitória, caracterizada pela dominação de si próprio, não implica no desaparecimento da vivacidade dos desejos e dos prazeres, sentimentos dominados de forma completa pelo sujeito temperante, é mais um governo que o indivíduo desenvolve sobre si. Foucault esclarece que o temperante, aquele que deseja com moderação e quando convém: “[...] não é aquele que não tem mais desejos, mas aquele que deseja 'com moderação, não mais do que convém, nem quando não convém" (FOUCAULT, 1984, p. 87). Dessa forma, Aristóteles (1984, p. 97) afirma que o homem temperante não aprecia as coisas proferidas pelo intemperante, e nem as que não devem, ele antes desenvolve uma relação consigo para que possa controlar seus próprios desejos. "Assim, para que o sujeito possa tornar-se temperante e vitorioso, é preciso existir uma relação de si para consigo. Relação essa que Foucault denomina de "heautocrática" ${ }^{6}$, citando o exemplo da vida doméstica, na qual o homem será temperante à 
medida que comandar seus desejos, como comanda seus serviçais.?

É plausível explicarmos que as formas de prazer existentes nos aphrodisia não se resumem especificamente naquilo que é considerado pecado (mau), mas também no que pode vir a ser um excesso, que é o caso do homem intemperante ${ }^{8}$. Assim, Foucault faz referência a Aristóteles, o qual se questiona na Ética a Nicômaco sobre quem são aqueles que merecem denominação de intemperantes. Para isso, Foucault (1984, p. 53) retoma uma definição restrita do que seria um indivíduo intemperante, segundo Aristóteles, fazendo parte "da intemperança, da akolasia, somente os prazeres do corpo". A concepção de comportamento sexual no gênero humano, especificamente na antiguidade, tem uma dinâmica que é definida pelo prazer no corpo, portanto os aphrodisia, ao que parece, são a forma como o indivíduo convive com os prazeres, sejam eles os prazeres corporais, $o$ de beber, o de comer e o das relações sexuais. "O homem que abstém dos prazeres do corpo, e se alegra com a própria abstenção é temperante" (ARISTÓTELES, 2013, p. 34). Essa é uma passagem que demonstra como deveria o homem agir na ética antiga perante o uso dos prazeres. De acordo com Aristóteles (2013, p. 66), a temperança, assim como a coragem, é uma virtude que fazem parte da parte irracional da alma e a prática da temperança é um meio-termo no que se refere ao uso dos prazeres. 
Os gregos condenavam a prática da intemperança, pois a intemperança, como já mencionamos, caracterizavase pelo excesso no que tange aos prazeres do corpo (tato, paladar, sexual). No entanto, é imprescindível salientarmos que ninguém era chamado de temperante, e aqui estamos falando especificamente da coragem, por enfrentar um perigo, ou de intemperante por fugir dele, mas antes, eram chamados de intemperantes aqueles que sofriam mais do que deviam quando alcançavam coisas agradáveis ou quando não alcançavam; e temperantes quando não sofriam com a falta do que é agradável. Desta maneira, esclarece Aristóteles:

O intemperante, portanto, anseia por todas as coisas agradáveis ou as que mais o são, e é levado pelo seu apetite escolhê-las custe o que custar; por isso sofre não apenas quando não as consegue, mas também quando simplesmente anseia por elas (pois o apetite é acompanhado pelo sofrimento), embora pareça um absurdo sofrer por causa do prazer (ARISTÓTELES, 2013, p. 69).

Destarte, o homem temperante é o contrário do homem intemperante, aquele que ocupa uma posição mediana quanto aos objetos de desejos, neste caso, não havendo a apreciação de forma excessiva e nem insuficiente. Não estamos aqui a dizer que o homem temperante não 
deva sofrer, e sim que esse homem sofre, porém de forma moderada, na medida em que lhe convém. Cabe ao mesmo, viver de forma obediente e disciplinada, sendo que, "o elemento apetitivo deve harmonizar-se com o princípio racional" (ARISTÓTELES, 2013, p. 71), de tal modo que sua ação de praticar algo ocorra de forma nobre, desejando os objetos da maneira e nas ocasiões certas, colocando a razão acima das emoções para então poder agir de forma correta.

De acordo com Foucault, o sujeito intemperante faz transparecer um dos traços fundamentais da ética da carne e da concepção de sexualidade, que seria a dissociação do conjunto prazer-desejo. Dissociação marcada pela omissão do prazer e pela problematização intensa do desejo, já na experiência dos aphrodisia, em compensação como afirma Foucault, ato, desejo e prazer formam um conjunto, desencadeando a prática dos prazeres, os quais têm elementos fortemente associados uns aos outros. O prazer associado ao ato pela mediação da natureza promove o desejo, o movimento que vai ao encontro do que "dá prazer", o qual se baseia no princípio lembrado por Aristóteles de que "o desejo é sempre da coisa agradável" (FOUCAULT, 1984, p. 56). Também para analisar o desejo, Foucault (1984, p. 56) retoma Platão, que insistia na perspectiva da coisa agradável. Platão (1984, p. 57) afirma, no Filebo, "que não poderia haver desejo sem privação, sem falta da coisa desejada e sem mescla, portanto, de um certo 
sofrimento: mas o apetite, só pode ser provocado pela representação, a imagem ou a lembrança da coisa que dá prazer".

Consoante Foucault (1984, p. 211), o bom casamento é aquele que é útil para a cidade, pois é no casamento que o homem encontra meios para ser um bom governante. Visto que, o homem que cuida bem de seu patrimônio terá condições suficientes para cuidar da cidade e governá-la. E assim, dando ênfase ao que já dissemos anteriormente, podemos salientar que com os antigos já existiam restrições no que se refere ao uso dos prazeres, sejam da ordem do casamento ou relações com os rapazes, no entanto, a finalidade dessas restrições eram outras que não as constituídas na moral cristã.

Em virtude do que foi mencionado, é plausível esclarecermos que ao analisar a ética antiga, Foucault não pretende ir em busca de uma alternativa nos gregos para a questão da moral sexual moderna. O que importa é uma problematização das questões, uma genealogia dos problemas éticos relacionados à moral sexual. Afim de que possamos entender como os antigos se portavam diante da prática dos prazeres, para compreender a moral da moderna, no que concerne a sexualidade. As práticas da cultura grega nos levam a pensar em uma vivência plena, que condizia com a forma que cada um deveria agir em sua conduta individual, um modo de vida que valoriza a prática 
de si, que se preocupava com a intensidade dos prazeres, bem mais do que com as normas de como praticar esses prazeres. Desse modo, a cultura antiga se preocupava no que diz respeito aos aphrodisia, com o modo pelo qual os indivíduos dirigiam suas atividades sexuais, o modo como os conduzia. Isso não se restringia a uma forma de lei que delimitava o que era proibido ou permitido, mas a uma questão de medir o modo como distribuir e controlar seus atos.

\section{NOTA}

${ }^{1}$ Mestranda em Filosofia pela Universidade Federal da Bahia (UFBA). Professora pela Secretaria de Educação estadual da Bahia. E-mail: lourinha.ana@hotmail.com.

${ }^{2}$ Foucault define os aphrodisia como os atos, os gestos, contatos que proporcionem alguma forma de prazer. FOUCAULT, O uso dos prazeres, p. 53.

${ }^{3}$ No presente texto analisaremos o casamento.

${ }^{4}$ Palavra grega que tem por significado: trabalho, zelo, cuidado por algo;

${ }^{5}$ Cf: FOUCAUlT, M. O cuidado de si, Rio de Janeiro: Paz e Terra, 2014 b, p. 58.

${ }^{6} \mathrm{O}$ indivíduo deve instaurar uma relação de si para consigo que é do tipo 'dominação-obediência', 'comando-submissão', 'domíniodocilidade'. (FOUCAULT, O uso dos prazeres, p. 87). 
${ }^{7}$ Foucault busca nos gregos a compreensão do duplo, partindo da forma heautocrática, que é uma compreensão do diagrama de poder encontrada na hierarquia grega, pois a formação grega apresenta novas relações de poder, que iriam atualizar seus regimes. Relações essas diferentes dos velhos imperiais, formando esse diagrama de poder que se estende através dos saberes qualificados.

${ }^{8} \mathrm{O}$ homem intemperante, consiste naquele homem abusa dos prazeres, que os usa de forma excessiva.

\section{REFERÊNCIAS BIBLIOGRÁFICAS}

ARISTÓTELES. Ética a Nicômaco. Trad. Torrieri Guimarães. 6a Ed. São Paulo: Martin Claret, 2013.

ARISTÓTELES. Ética a Nicômaco. Coleção Os Pensadores. Trad. Leonel Vallandro. Porto Alegre: Globo S. A, 1984.

ARISTÓTELES. Política. Trad. Mario da Gama Kury. Brasília: Universidade de Brasília, 1985.

BIRMAN, Joel. Entre Cuidado e Saber de Si: Sobre Foucault e a Psicanálise. 2a Ed. Rio de Janeiro: Relume Dumará, 2000.

DELEUZE, Gilles. Foucault. Trad. Sob. A direção de Claudia Sant'Anna Martins. São Paulo: Editora Brasiliense, 1988. 
DÍAZ, Esther. A filosofia de Michel Foucault. Trad. Cesar Candiotto. $1^{\text {a }}$ Ed. São Paulo: Unesp, 2012.

EDGARDO, Castro. El Vocabulário de Michel Foucault: Um recorrido alfabético por sus temas, conceptos y autores.

FOUCAULT. Michel. História da sexualidade I: A vontade de saber. Tradução de Maria Thereza Albuquerque e J. A. Albuquerque. $1^{\text {a }}$ Ed. Rio de Janeiro: Paz e Terra, 2014a.

FOUCAULT, Michel. História da Sexualidade II: O uso dos prazeres. Trad. Sob a direção de Maria Thereza da Costa Albuquerque. Rio de Janeiro: editora Graal, 1984. V. 2.

FOUCAULT, Michel. História da Sexualidade III: O cuidado de si. Tradução de Maria Thereza Albuquerque e J. A. Albuquerque. $1^{\text {a }}$ Ed. Rio de Janeiro: Paz e Terra, 2014b.

FOUCAULT, Michel. Em defesa da sociedade. Curso no College de France. Trad. Maria Galvão. São Paulo: Martins Fontes, 1999.

FOUCAULT, Michel. Estratégia, poder-saber: organização de textos e seleção Manoel Barros Motta; tradução: Vera Lucia Avellar Ribeiro. 2. Ed. Rio de Janeiro: Forense Universitária, 2006. Volume IV.

FOUCAULT, Michel. Estratégia, poder-saber: organização de textos e seleção Manoel Barros Motta; tradução: Vera Lucia Avellar Ribeiro. 2. Ed. Rio de Janeiro: Forense Universitária, 2015. Volume IV.

FOUCAULT, Michel. Ética, sexualidade, política: organização de textos Manoel Barros da Motta; tradução: Elisa Monteiro, Inês 
Autran Dourado Barbosa. 3. Ed. Rio de Janeiro: Forense Universitária, 2014c.Volume V.

FOUCAULT, Michel. Genealogia da ética, subjetividade $e$ sexualidade: organização de textos e seleção Manoel Barros da Motta; tradução: Abner Chiquieri. Rio de Janeiro: Forense Universitária, 2014d. Volume IX.

FOUCAULT. M. Microfísica do poder. Rio de Janeiro: Graal, 1978. p. 127-137.

RODRIGUES, Malcom Guimaraes. Foucault e a transgressão do prazer na ética da psicanalise lacaniana. Salvador: Edufba, 2015.

RABINOW, Paul; DREYFUS, Hubert. Michel Foucault Uma trajetória Filosófica: Para além do estruturalismo e da hermenêutica. Trad. Sob a direção de Vera Porto Carrero. Forense Universitária. 1979.

REVEL, Judith. Foucault Conceitos Essenciais. Trad. Sob a direção de Carlos Piovezani Filho e Nilton Milanez. São Carlos: Editora Claraluz, 2005. 96p.

TEMPLE, Giovana Carmo. Acontecimento, poder e resistência em Michel Foucault. Cruz das Almas, Bahia: UFRB, 2013.

ZINGANO, Marco. Sobre a ética nicomaqueia de Aristóteles: textos selecionados. Coordenação. Marco Zingano. São Paulo: Odysseus, 2010. 